This item was submitted to Loughborough's Research Repository by the author.

Items in Figshare are protected by copyright, with all rights reserved, unless otherwise indicated.

\title{
Infant weight gain and adolescent body mass index: comparison across two British cohorts born in 1946 and 2001
}

PLEASE CITE THE PUBLISHED VERSION

http://dx.doi.org/10.1136/archdischild-2017-314079

\section{PUBLISHER}

(C) The authors. Published by BMJ Publishing Group

\section{VERSION}

AM (Accepted Manuscript)

\section{PUBLISHER STATEMENT}

This work is made available according to the conditions of the Creative Commons Attribution-NonCommercialNoDerivatives 4.0 International (CC BY-NC-ND 4.0) licence. Full details of this licence are available at: https://creativecommons.org/licenses/by-nc-nd/4.0/

\section{LICENCE}

CC BY-NC-ND 4.0

\section{REPOSITORY RECORD}

Johnson, Will, David Bann, and Rebecca Hardy. 2019. "Infant Weight Gain and Adolescent Body Mass Index: Comparison Across Two British Cohorts Born in 1946 and 2001”. figshare. https://hdl.handle.net/2134/32570. 
Infant weight gain and adolescent body mass index: comparison across two British cohorts born in 1946 and 2001

William Johnson ${ }^{1 *}$, David Bann², Rebecca Hardy ${ }^{3}$

* Corresponding author

${ }^{1}$ School of Sport, Exercise and Health Sciences, Loughborough University, Epinal Way, Loughborough, LE11 3TU, UK. W.O.Johnson@lboro.ac.uk +44(0) 1509228 057

${ }^{2}$ Centre for Longitudinal Studies, UCL Institute of Education, 55-59 Gordon Square, London, WC1H OAL, UK

${ }^{3}$ MRC Unit for Lifelong Health and Ageing at UCL, 33 Bedford Place, London, WC1B $5 J U$, UK

Word Count: 2941 


\section{ABSTRACT}

\section{Objective}

To investigate how the relationship of infant weight gain with adolescent body mass index (BMI) differs for individuals born during compared to before the obesity epidemic era.

\section{Design}

Data from two British birth cohorts, the 1946 National Survey of Health and Development (NSHD, $n=4,199)$ and the 2001 Millennium Cohort Study (MCS, $n=$ $9,417)$, were used to estimate and compare associations of infant weight gain between ages 0-3 years with adolescent outcomes.

\section{Main outcome measures}

BMI Z-scores and overweight/ obesity at ages 11 and 14 years.

\section{Results}

Infant weight gain, in Z-scores, was positively associated with adolescent BMI Zscores in both cohorts. Non-linearity in the MCS meant that associations were only stronger than in the NSHD when infant weight gain was above -1 Z-score. Using decomposition analysis, between-cohort differences in association accounted for 20$30 \%$ of the differences (secular increases) in BMI Z-scores, although the underlying estimates were not precise with 95\% confidence intervals $(\mathrm{Cl})$ crossing zero. Conversely, between-cohort differences in the distribution of infant weight gain accounted for approximately $9 \%$ of the differences (secular increases) in BMI Z- 
scores, and the underlying estimates were precise with 95\% $\mathrm{Cl}$ not crossing zero. Relative to normal weight gain (change of -0.67 to +0.67 Z-scores between ages $0-3$ years), very rapid infant weight gain $(>1.34)$, but not rapid weight gain $(+0.67$ to $+1.34)$, was associated with higher BMI Z-scores more strongly in the MCS $(\beta=$ $0.790 ; 95 \% \mathrm{Cl}=0.717,0.862$ at age 11 years) than the $\operatorname{NSHD}(0.573 ; 0.466,0.681)$; $p<0.001$ for between-cohort difference. The relationship of slow infant weight gain $(<-0.67)$ with lower adolescent BMI was also stronger in the MCS. Very rapid or slow infant weight gain were not, however, more strongly associated with increased risk of adolescent overweight/ obesity or thinness, respectively, in the more recently born cohort.

\section{Conclusions}

Greater infant weight gain, at the middle/ upper-end of the distribution, was more strongly associated with higher adolescent BMI among individuals born during (compared to before) the obesity epidemic. Combined with a secular change toward greater infant weight gain, these results suggest that there are likely to be associated negative consequences for population-level health and wellbeing in the future, unless effective interventions are developed and implemented. 


\section{WHAT IS ALREADY KNOWN ON THIS TOPIC}

By adolescence, overweight/ obesity prevalence in the United Kingdom is already 23 times greater in cohorts born into (compared to before) the obesity epidemic.

Rapid infant weight gain is associated with greater body mass index (BMI) later in life and increased risk for overweight/ obesity.

However, it is unknown whether or not these associations are accentuated for individuals born during, compared to before, the obesity epidemic.

\section{WHAT THIS STUDY ADDS}

Greater infant weight gain, at the middle/ upper-end of the distribution, was more strongly associated with higher adolescent BMI in the 2001 than 1946 British birth cohort.

Using decomposition analysis, this between-cohort difference in strength of association accounted for $23 \%$ of the difference (secular increase) in BMI at age 11 years between 1957 and 2012, although the underlying estimates were not precise with $95 \%$ confidence intervals $(\mathrm{Cl})$ crossing zero.

Conversely, between-cohort differences in the distribution of infant weight gain accounted for approximately $9 \%$ of the differences (secular increases) in BMI Zscores, and the underlying estimates were precise with 95\% Cl not crossing zero. 
Very rapid infant weight gain (> two centile bands) was more strongly related to greater adolescent BMI (but not overweight/ obesity) in the 2001 cohort. 


\section{INTRODUCTION}

The obesity epidemic is a major public health threat.[1] In the United Kingdom (UK), we have previously demonstrated a secular trend toward higher body mass index (BMI) at increasingly younger ages, such that, by adolescence, overweight/ obesity prevalence is already 2-3 times higher in cohorts born into, compared to before, the obesity epidemic.[2] This is particularly concerning given evidence that adolescent obesity tracks into and across adulthood and is associated with the development of various non-communicable disease risk factors.[3-6]

Rapid infant weight gain, most commonly defined as upward crossing through one UK centile band in the first few years of life, has consistently been found to be associated with increased risk of overweight/ obesity in childhood, adolescence, and adulthood.[7-10] Further, the relationship of infant weight gain with subsequent obesity is stronger than that for most other risk factors,[11 12] and after accounting for infant weight gain, in addition to sex and birth weight, other risk factors (e.g., maternal BMI and gestational diabetes) don't substantially improve obesity prediction.[8 13-15] It is possible, therefore, that rapid infant weight gain contributed to the development of the obesity epidemic. And evidence of this would be indicated by a change over time in the distribution of infant weight gain and/ or its association with future BMI. Rugholm et al[16] tested this idea for birth weight but found no evidence that changes in its distribution or effect explained the secular increase in childhood overweight in Denmark, thereby strengthening the rationale for examining postnatal growth. 
Using two British birth cohorts, we aimed to examine how the relationship of infant weight gain with adolescent BMI differs for individuals born during, compared to before, the obesity epidemic era. Evidence of a strengthening association over time would indicate that the adverse consequences of rapid infant weight gain might be accentuated in obesogenic environments.

\section{METHODS}

\section{Study samples}

The 1946 Survey of Health and Development (NSHD) is based on a sample $(n=$ 5,362) born in one week in March 1946 in England, Scotland, and Wales, comprising all singleton births from females with husbands in non-manual and agricultural employment and a random selection of one in four singleton births to females with husbands in manual employment. The 2001 Millennium Cohort Study (MCS) is based on 18,818 people born between September 2000 and January 2002 who were living in the England, Scotland, Wales, or Northern Ireland at age nine months. Both studies have received ethical approval and obtained informed parental and/ or participant consent.[17-19]

Twins/ triplets ( $n=522$ ), non-white ethnicity participants $(n=3,207)$, and individuals from Northern Ireland $(n=1,881)$ in the 2001 MCS were removed to improve comparability to the 1946 NSHD. Individuals without a single measurement of adolescent BMI (see Outcomes) were also dropped (NSHD $n=1,163$; $\operatorname{MCS} n=$ 3,791). The resulting sample size in each study (NSHD $n=4,199 ; \operatorname{MCS} n=9,417$ ) 
represents more than $80 \%$ of the individuals still participating at the most recent sweep used in this paper.

\section{Exposure}

Birth weights were extracted from medical records in the 1946 NSHD and were collected from the main carer in the 2001 MCS at the first sweep. Reported birth weights in the 2001 MCS have been shown to demonstrate a high level of agreement with registration data.[20] Subsequently, weight was measured at two and four years of age in the 1946 NSHD and three years of age in the 2001 MCS. All measurements were converted to Z-scores according to the World Health Organisation (WHO) Child Growth Standards.[21] Linear interpolation was used to estimate weight Z-score at age three years (i.e., Z-score at four years - Z-score at two years / two) in the 1946 NSHD. A continuous exposure was then calculated as change in infant weight Z-score between ages 0-3 years in both studies. A categorical exposure was also computed to identify infants with slow $(<-0.67 \mathrm{Z-}$ scores), normal $(-0.67$ to +0.67$)$, rapid $(+0.67$ to +1.34$)$, and very rapid weight gain $(>+1.34)$. A change of 0.67 or 1.34 Z-scores represents shifting upward/ downward through one or two, respectively, UK centile bands.

\section{Outcomes}

Weight and height were measured at sweeps at ages 11 and 14-15 years in the 1946 NSHD and ages 11 and 14 years in the 2001 MCS. Herein, we refer to ages 11 and 14 years in both studies for ease. BMI was calculated as weight $(\mathrm{kg}) /$ height $(\mathrm{m})^{2}$ and BMI Z-scores were computed according to the World Health Organisation 
(WHO) Child Growth References.[22] Thinness, overweight, and obesity were defined according to International Obesity Task Force (IOTF) cut-offs.[23-25]

\section{Potential confounders}

In addition to birth weight Z-score and sex, maternal BMI and socio-economic position (SEP) were considered. Maternal BMI was based on self-reported weight and height at age six years in the 1946 NSHD, and pre-pregnancy weight and height self-reported by the mothers at age nine months in the 2001 MCS. SEP was indicated by father's occupation at age 11 years, classified according to the Registrar General's Social Class (I professional, II managerial and technical, IIIN skilled nonmanual, IIIM skilled manual, IV partly-skilled, and V unskilled). In order to minimize missing data, mother-figure occupational class was used in the 2001 MCS where no father-figure was present in the household $(n=1,703)$.

\section{Statistical analysis}

To account for missing information (Table 1), analytical models were applied to multiple-imputed data (see Appendix 1 for full details). Briefly, imputation of 20 datasets was performed for each cohort separately using chained equations, before fitting the analytical models and combining estimates.

General linear regression models were used to test the associations of both the continuous and categorical infant weight gain exposures, separately, with adolescent BMI Z-scores. A consistent non-linear relationship (stronger at the middle/ upper-end of the exposure distribution) between infant weight Z-score change and adolescent BMI Z-scores was found in exploratory analyses in the 2001 MCS. This non-linearity 
was parameterised, in both cohorts for comparability, using linear splines; a knot point of -1 Z-score was chosen pragmatically based on visual inspection of the regression curves as the point where the associations changed. This approach results in two linear terms which are easily-interpretable, so was preferred over other functions used to fit smooth curves (e.g., restricted cubic splines). Multinomial logistic regression models were developed to test the associations of the categorical infant weight gain exposure with adolescent overweight/ obesity and thinness compared to normal weight; estimates are presented as relative risk ratios. After running unadjusted models, adjustments were made 1) for birth weight Z-score, sex, and exact age of outcome assessment and then 2) additionally for maternal BMI and father's occupational class. For parsimony, occupational class was converted to cohort-specific ridit scores; associated regression estimates capture the difference in outcome between the lowest and highest SEP, termed the slope index of inequality.[26] All regression models were stratified by cohort, and between-cohort differences were subsequently estimated and tested for statistical significance against the t-distribution, with the null hypothesis that they were equal to zero.

To understand the extent to which any difference between cohorts in the relationship of infant weight gain with adolescent BMI might explain the secular increase in adolescent BMI, Blinder-Oaxaca three-way decomposition was employed.[27] Briefly, this technique decomposes the difference in mean linear predictions between two groups (from separate regression models) into 1) the part due to different characteristics (i.e., values of the independent variables), 2) the part due to different coefficients (i.e., strengths of association), and 3) an interaction term that measures the simultaneous effect of differences in characteristics and coefficients, which is 
essentially error. The decomposition was applied using the fully-adjusted infant weight Z-score change and adolescent BMI Z-scores regression models, and we present characteristics, coefficients, and interaction estimates for infant weight Zscore change.

As sensitivity analyses, all models were refitted three times, firstly, using infant weight Z-score change variables (between ages 0-2 and 0-4 years) in the 1946 NSHD that didn't rely on interpolated data, secondly, using sampling weights that account for the survey designs of the studies and, thirdly, using only complete-cases (i.e., no missing data).

All procedures were performed in Stata 14 (StataCorp LP, College Station, TX, USA).

\section{RESULTS}

Adolescent overweight/ obesity was more prevalent in the 2001 MCS compared to the 1946 NSHD (e.g., 26.3 vs $8.8 \%$ at age 11 years), as was very rapid infant weight gain (17.5 vs 13.9\%) (Table 1$)$.

Adjustment of regression models did not substantially change the results, so the unadjusted exposure estimates are shown in Supplementary Tables 3-5 and only the fully-adjusted exposure estimates are reported here; estimates for the potential confounders are shown in Supplementary Tables 6-8. 
Infant weight Z-score change was positively associated with adolescent BMI Zscores at both time points and in both cohorts (Table 2). Within the 2001 MCS, the associations were, however, stronger at the middle/ upper-end of the exposure distribution. For example, at age 11 years, the estimate was 0.349 (95\% confidence interval $(\mathrm{Cl})=0.253,0.495)$ if infant weight change was less than -1 Z-score, but above this threshold, the estimate was $0.523(0.495,0.551)$. As a result, while there were no differences between the two cohorts in estimated effect sizes at the lower end of the exposure distribution, the estimated effect sizes at the middle/ upper-end of the exposure distribution were significantly larger in the 2001 MCS compared to the 1946 NSHD (e.g., by 0.105 (0.052, 0.159) BMI Z-scores at age 14 years). Consequently, in terms of clinically relevant groups, very rapid infant weight gain was more strongly associated with higher adolescent BMI in the more recently born cohort (e.g., by $0.217(0.092,0.342)$ BMI Z-scores at age 14 years) (Table 3). Conversely, the relationship of slow infant weight gain with lower adolescent BMI was also more pronounced in the 2001 MCS. No evidence, however, was found to suggest that very rapid infant weight gain incurred greater risk for overweight/ obesity in the 2001 MCS compared to the 1946 NSHD (Table 4), or that slow infant weight gain incurred greater risk for thinness in the 2001 MCS compared to the 1946 NSHD (Supplementary Table 9).

Table 5 shows the results of the decomposition analysis. The differences between cohorts in the mean linear predictions, using the models in Table 2, capture the extent to which adolescent BMI was higher in the 2001 MCS compared to the 1946 NSHD. Characteristics reflect the increase in BMI Z-score in the 1946 NSHD if that cohort had the same infant weight Z-score change values as the 2001 MCS. This 
part of the decomposition, therefore, demonstrates that $9 \%$ (i.e., $0.051 / 0.561$ ) of the between-cohort difference (i.e., secular increase) in adolescent BMI at age 11 years was due to a change in the distribution of infant weight gain. Coefficients reflect the increase in BMI Z-score in the 1946 NSHD when applying the 2001 MCS coefficients to the 1946 NSHD infant weight Z-score change values. This part of the decomposition, therefore, demonstrates that 23\% (i.e., $0.127 / 0.561$ ) of the difference was due to a change in the relationship of infant weight gain with adolescent BMI. Results for BMI age at 14 years also showed that the estimated secular increase was more due to a change in the effect of infant weight gain than its distribution. Note, however, that the estimates for the coefficients were less precise than those for the characteristics, with $95 \% \mathrm{Cl}$ crossing zero.

Results did not noticeably change in sensitivity analyses (data not shown).

\section{DISCUSSION}

There is a paucity of knowledge on how the consequences of early-life risk factors for overweight/ obesity and adiposity-related diseases might have changed over time. We investigated the relationship of infant weight gain with adolescent BMI in two cohorts, one born in 1946, well-before the obesity epidemic era, and one born in 2001, well-into the obesity epidemic era. The key finding was that 1) greater infant weight gain, at the middle/ upper-end of the distribution, was more strongly associated with higher adolescent BMI in the more recently born cohort and that 2) this between-cohort difference in strength of association accounted for $20-30 \%$ of the estimated between-cohort difference (i.e., secular increase) in adolescent BMI, 
although the underlying estimates were not precise with $95 \% \mathrm{Cl}$ crossing zero. In terms of clinically relevant groups, very rapid infant weight gain ( $>$ two centile bands) was more strongly related to higher adolescent BMI in the 2001 cohort compared to the 1946 cohort. The same was not true for overweight/ obesity outcomes, although this may reflect a lack of power due to the relatively small number of overweight/ obese adolescents within each infant weight gain category in the 1946 NSHD (e.g., $n$ = 52 with very rapid infant weight gain and overweight/ obesity at age 11 years, using observed data).

Our results also demonstrate a shift over time in the distribution of infant weight Zscore change, such that average values and variation were greater in the 2001 MCS (mean 0.29, SD 1.25) compared to the 1946 NSHD (mean 0.20, SD 1.11). The greater variation might go some way to explaining why the associations of both slow and very rapid infant weight gain, with adolescent BMI, were more pronounced in the more recently born cohort. This change in distribution also contributed to the secular increase in adolescent BMI, but to a lesser yet more precisely estimated extent than the observed change in strength of association.

The key findings were observed despite adjusting for potential confounders which could have biased the estimated associations more so in one cohort than the other, for example, due to higher maternal BMI in the 2001 MCS than the 1946 NSHD. Further research is therefore required to understand why the relationship of infant weight gain with adolescent obesity appears to have strengthened over time. If this phenomenon is not explained by different confounding structures, then we need to understand the underlying biological mechanism(s). It may be, for example, that the 
composition (fat vs fat-free mass) of infant weight gain (and thus its relationship with future BMI) has changed over time or that genetic regulation of the overweight/ obesity development process has strengthened.[28-30]

It is well known that rapid infant weight gain is a risk factor for subsequent overweight/ obesity, $[7-10]$ and evidence in the present paper strengthens the rationale for targeting rapid infant weight gain as part of obesity prevention programmes. Because of tracking,[3] the observed between-cohort difference in adolescent BMI (due to infant weight gain) may not attenuate substantially/ quickly with age and may have long-term consequences for health. Results of a recently published responsive parenting intervention (including messages about infant feeding, sleep hygiene, active social play, emotion regulation, and growth record education) to prevent rapid infant weight gain have been promising.[31] Longer term follow-up is, however, needed to understand whether or not such interventions to prevent rapid infant weight gain also translate into reduced risk of childhood, adolescent, and adulthood obesity and related diseases.

In a meta-analysis of individual-level data on 47,661 participants from 10 cohort studies, Druet et al[8] found little evidence of heterogeneity in the effect of infant weight gain between birth and age one year on childhood obesity. Between-study differences (e.g., in population and age at outcome assessment) may have, however, masked any secular trend. The possibility of such masking was limited in the present paper by conducting co-ordinated analysis of comparable, harmonised data (e.g., adolescent BMI at similar ages) collected on two comparable birth cohort studies (e.g., both designed to be nationally representative at booking) initiated 55 
years apart. For the same reason, it is unlikely that our key findings are attributable to fundamental differences in design between the two studies.

In terms of limitations, BMI is only an indicator of adiposity, and it is possible that our findings reflect a stronger effect of infant weight gain on fat-free mass (instead of/ in addition to fat mass) in the more recently born cohort.[32 33] The 1946 NSHD cohort were, of course, recruited following the Second World War and during a period of rationing, but because rapid weight gain following undernutrition is related to increased risk for obesity,[34 35] the specific time course of the older cohort may have been more likely to produce null findings than alternative findings. The inclusion of additional British birth cohorts born between 1946 and 2001 could have improved robustness, but unfortunately the first measurements of weight (after birth) in the 1958 and 1970 cohorts are at ages seven and 10 years, respectively. Even in the 1946 NSHD, interpolation was required to estimate weight at age three years. This could have potentially biased the reported associations but sensitivity analyses, using infant weight gain variables (between ages 0-2 and 0-4 years) that didn't use interpolated data, suggest that this is unlikely. It is, however, possible that the age range used to define infancy (i.e., 0-3 years) isn't the most important for weight gain (and its consequences for subsequent $\mathrm{BMI}$ ) and results might have been different if we studied another period (e.g., 0-1 year).[36] Systematic patterns of missing data could have also biased the results, but this problem was addressed using multiple imputation.

In conclusion, our results show how the relationship of infant weight gain with adolescent BMI in Great Britain was stronger among a cohort born into the obesity 
epidemic (compared to a cohort born well-before the obesity epidemic). The adverse consequences of gaining too much weight during infancy might, therefore, be more pronounced for recent and future generations than previously thought based on analyses of historical birth cohort studies. Combined with a secular change toward greater infant weight gain, these results suggest that there are likely to be associated negative consequences for population-level health and wellbeing in the future, unless effective interventions are developed and implemented. 


\section{ACKNOWLEDGEMENTS}

WJ is supported by a UK Medical Research Council (MRC) New Investigator Research Grant (MR/P023347/1), and acknowledges support from the National Institute for Health Research (NIHR) Leicester Biomedical Research Centre, which is a partnership between University Hospitals of Leicester NHS Trust, Loughborough University, and the University of Leicester. DB is supported by the Economic and Social Research Council (grant numbers ES/M008584/1 and ES/M001660/1) and the Academy of Medical Sciences/the Wellcome Trust "Springboard Health of the public in 2040" Award [HOP001\1025]. The funders had no role in study design, data collection and analysis, decision to publish, or preparation of the manuscript. The UK MRC provides core funding for the MRC National Survey of Health and Development and for RH (MC_UU_12019/1, MC_UU_12019/2). We thank the participants of the birth cohort studies and the staff who were involved in collecting the data.

\section{COMPETING INTERESTS}

None.

\section{FUNDING}

None.

\section{CONTRIBUTORSHIP STATEMENT}

WJ conceptualized the study, carried out the analyses, and drafted the initial manuscript. WJ, DB, and $\mathrm{RH}$ made substantial contributions to the interpretation of the data, revised the manuscript critically for important intellectual content, gave final 
approval of the version to be published, and agree to be accountable for all aspects of the work.

\section{DATA SHARING STATEMENT}

This research uses harmonised data from two cohort studies. The original and harmonised 1946 NSHD data (doi:10.5522/NSHD/Q101) are made available to researchers who submit data requests to mrclha.swiftinfo@ucl.ac.uk; see also the full policy documents at http://www.nshd.mrc.ac.uk/data.aspx. The original data for the 2001 MCS are available from the UK Data Archive (http://www.dataarchive.ac.uk). 


\section{REFERENCES}

1. GBD 2015 Obesity Collaborators, Afshin A, Forouzanfar MH, et al. Health Effects of Overweight and Obesity in 195 Countries over 25 Years. N Engl J Med 2017;377(1):13-27. 2. Johnson W, Li L, Kuh D, et al. How Has the Age-Related Process of Overweight or Obesity Development Changed over Time? Co-ordinated Analyses of Individual Participant Data from Five United Kingdom Birth Cohorts. PLoS Med 2015;12(5):e1001828; discussion e28.

3. Aarestrup J, Bjerregaard LG, Gamborg M, et al. Tracking of body mass index from 7 to 69 years of age. Int J Obes (Lond) 2016;40(9):1376-83.

4. Hardy R, Ghosh AK, Deanfield J, et al. Birthweight, childhood growth and left ventricular structure at age 60-64 years in a British birth cohort study. Int J Epidemiol 2016;45(4):1091102.

5. Johnson $\mathrm{W}$, Kuh $\mathrm{D}$, Tikhonoff $\mathrm{V}$, et al. Body mass index and height from infancy to adulthood and carotid intima-media thickness at 60 to 64 years in the 1946 British Birth Cohort Study. Arterioscler Thromb Vasc Biol 2014;34(3):654-60.

6. Murray ET, Hardy R, Hughes A, et al. Overweight across the life course and adipokines, inflammatory and endothelial markers at age 60-64 years: evidence from the 1946 birth cohort. Int J Obes (Lond) 2015;39(6):1010-8.

7. Baird J, Fisher D, Lucas $P$, et al. Being big or growing fast: systematic review of size and growth in infancy and later obesity. BMJ 2005;331(7522):929.

8. Druet C, Stettler N, Sharp S, et al. Prediction of childhood obesity by infancy weight gain: an individual-level meta-analysis. Paediatr Perinat Epidemiol 2012;26(1):19-26.

9. Monteiro PO, Victora CG. Rapid growth in infancy and childhood and obesity in later life-a systematic review. Obes Rev 2005;6(2):143-54.

10. Ong KK, Loos RJ. Rapid infancy weight gain and subsequent obesity: systematic reviews and hopeful suggestions. Acta Paediatr 2006;95(8):904-8. 
11. Monasta L, Batty GD, Cattaneo A, et al. Early-life determinants of overweight and obesity: a review of systematic reviews. Obes Rev 2010;11(10):695-708.

12. Weng SF, Redsell SA, Swift JA, et al. Systematic review and meta-analyses of risk factors for childhood overweight identifiable during infancy. Arch Dis Child 2012;97(12):1019-26.

13. Santorelli G, Petherick ES, Wright J, et al. Developing prediction equations and a mobile phone application to identify infants at risk of obesity. PLoS One 2013;8(8):e71183.

14. Rudolf M. Predicting babies' risk of obesity. Arch Dis Child 2011;96(11):995-7.

15. Weng SF, Redsell SA, Nathan D, et al. Estimating overweight risk in childhood from predictors during infancy. Pediatrics 2013;132(2):e414-21.

16. Rugholm S, Baker JL, Olsen LW, et al. Stability of the association between birth weight and childhood overweight during the development of the obesity epidemic. Obes Res 2005;13(12):2187-94.

17. Kuh D, Pierce M, Adams J, et al. Cohort profile: updating the cohort profile for the MRC National Survey of Health and Development: a new clinic-based data collection for ageing research. Int J Epidemiol 2011;40(1):e1-9.

18. Wadsworth M, Kuh D, Richards M, et al. Cohort Profile: The 1946 National Birth Cohort (MRC National Survey of Health and Development). Int J Epidemiol 2006;35(1):49-54.

19. Hansen K. Millennium Cohort Study: first, second, third, fourth, and fifth surveys: a guide to the datasets (8th edition). London, UK: Centre for Longitudinal Studies at the UCL Institute of Education, 2014.

20. Tate AR, Dezateux C, Cole TJ, et al. Factors affecting a mother's recall of her baby's birth weight. Int J Epidemiol 2005;34(3):688-95.

21. WHO Multicentre Growth Reference Study Group. WHO Child Growth Standards: Methods and Development: Length/Height-for-Age, Weight-for-age, Weight-for-Length, Weight-for-Height and Body Mass Index-for-Age. Geneva, Switzerland: World Health Organisation 2006. 
22. de Onis M, Onyango AW, Borghi E, et al. Development of a WHO growth reference for school-aged children and adolescents. Bull World Health Organ 2007;85(9):660-7.

23. Cole TJ, Bellizzi MC, Flegal KM, et al. Establishing a standard definition for child overweight and obesity worldwide: international survey. BMJ 2000;320(7244):1240-3.

24. Cole TJ, Flegal KM, Nicholls D, et al. Body mass index cut offs to define thinness in children and adolescents: international survey. BMJ 2007;335(7612):194.

25. Cole TJ, Lobstein T. Extended international (IOTF) body mass index cut-offs for thinness, overweight and obesity. Pediatr Obes 2012;7(4):284-94.

26. Mackenbach JP, Kunst AE. Measuring the magnitude of socio-economic inequalities in health: an overview of available measures illustrated with two examples from Europe. Soc Sci Med 1997;44(6):757-71.

27. Jann B. The Blinder-Oaxaca decomposition for linear regression models. The Stata Journal 2008;8(4):453-79.

28. Demerath EW, Choh AC, Johnson W, et al. The positive association of obesity variants with adulthood adiposity strengthens over an 80-year period: a gene-by-birth year interaction. Hum Hered 2013;75(2-4):175-85.

29. Johnson W, Choh AC, Lee M, et al. Characterization of the infant BMI peak: sex differences, birth year cohort effects, association with concurrent adiposity, and heritability. Am J Hum Biol 2013;25(3):378-88.

30. Olds TS. One million skinfolds: secular trends in the fatness of young people 1951-2004. Eur J Clin Nutr 2009;63(8):934-46.

31. Savage JS, Birch LL, Marini M, et al. Effect of the INSIGHT Responsive Parenting Intervention on Rapid Infant Weight Gain and Overweight Status at Age 1 Year: A Randomized Clinical Trial. JAMA Pediatr 2016;170(8):742-9.

32. Bann D, Wills A, Cooper $R$, et al. Birth weight and growth from infancy to late adolescence in relation to fat and lean mass in early old age: findings from the MRC National Survey of Health and Development. Int J Obes (Lond) 2014;38(1):69-75. 
33. Johnson W, Choh AC, Lee M, et al. Is infant body mass index associated with adulthood body composition trajectories? An exploratory analysis. Pediatr Obes 2017;12(1):10-18.

34. Ravelli AC, van Der Meulen JH, Osmond C, et al. Obesity at the age of $50 \mathrm{y}$ in men and women exposed to famine prenatally. Am J Clin Nutr 1999;70(5):811-6.

35. Ravelli GP, Stein ZA, Susser MW. Obesity in young men after famine exposure in utero and early infancy. N Engl J Med 1976;295(7):349-53.

36. Odegaard AO, Choh AC, Nahhas RW, et al. Systematic examination of infant size and growth metrics as risk factors for overweight in young adulthood. PLoS One 2013;8(6):e66994. 
Table 1. Descriptive statistics, by birth cohort study

\begin{tabular}{|c|c|c|c|c|c|c|}
\hline & & 1946 NSHD & 2001 MCS & & $\begin{array}{c}1946 \text { NSHD } \\
(n=4,199)\end{array}$ & $\begin{array}{l}2001 \mathrm{MCS} \\
(n=9,417)\end{array}$ \\
\hline & & & & $P$-value & \multicolumn{2}{|c|}{$\%$ missing data } \\
\hline Sex & & & & 0.082 & 0.0 & 0.0 \\
\hline Male & $n(\%)$ & $2,205(52.5)$ & $4,793(50.9)$ & & & \\
\hline Female & $n(\%)$ & $1,994(47.5)$ & $4,624(49.1)$ & & & \\
\hline Birth weight $(\mathrm{kg})$ & Mean (SD) & $3.40(0.51)$ & $3.40(0.56)$ & 0.918 & 0.4 & 0.1 \\
\hline Birth weight Z-score & Mean (SD) & $0.18(1.05)$ & $0.20(1.14)$ & 0.234 & 0.5 & 0.7 \\
\hline Infant weight Z-score change & Mean (SD) & $0.20(1.11)$ & $0.29(1.25)$ & $<0.001$ & 20.3 & 13.4 \\
\hline Categorised infant weight Z-score change & & & & $<0.001$ & 20.3 & 13.4 \\
\hline$<-0.67$ (slow) & $n(\%)$ & $724(21.6)$ & $1,713(21.0)$ & & & \\
\hline-0.67 to +0.67 (normal) & $n(\%)$ & $1,532(45.8)$ & $3,647(44.7)$ & & & \\
\hline+0.67 to +1.34 (rapid) & $n(\%)$ & $624(18.7)$ & $1,375(16.9)$ & & & \\
\hline$>+1.34$ (very rapid) & $n(\%)$ & $465(13.9)$ & $1,425(17.5)$ & & & \\
\hline Adolescent age at 11 years & Mean (SD) & $10.86(0.09)$ & $11.18(0.34)$ & $<0.001$ & 6.2 & 4.9 \\
\hline Adolescent BMI $\left(\mathrm{kg} / \mathrm{m}^{2}\right)$ at age 11 years & Median (IQR) & $16.91(15.79,18.39)$ & $18.38(16.61,20.99)$ & $<0.001$ & 6.2 & 4.9 \\
\hline Adolescent BMI Z-score at age 11 years & Mean (SD) & $0.00(1.01)$ & $0.56(1.18)$ & $<0.001$ & 6.2 & 4.9 \\
\hline Adolescent weight status at age 11 years & & & & $<0.001$ & 6.2 & 4.9 \\
\hline Thinness & $n(\%)$ & $420(10.7)$ & $534(6.0)$ & & & \\
\hline Normal weight & $n(\%)$ & $3,169(80.5)$ & $6,067(67.7)$ & & & \\
\hline Overweight & $n(\%)$ & $297(7.5)$ & $1,817(20.3)$ & & & \\
\hline Obesity & $n(\%)$ & $51(1.3)$ & $540(6.0)$ & & & \\
\hline Adolescent age at 14 years & Mean (SD) & $14.54(0.18)$ & $14.27(0.34)$ & $<0.001$ & 14.7 & 19.5 \\
\hline Adolescent BMI $\left(\mathrm{kg} / \mathrm{m}^{2}\right)$ at age 14 years & Median (IQR) & $19.67(18.26,21.47)$ & $20.48(18.63,23.31)$ & $<0.001$ & 14.7 & 19.5 \\
\hline Adolescent BMI Z-score at age 14 years & Mean (SD) & $0.01(0.95)$ & $0.43(1.15)$ & $<0.001$ & 14.7 & 19.5 \\
\hline
\end{tabular}




\begin{tabular}{|c|c|c|c|c|c|c|}
\hline Adolescent weight status at age 14 years & & & & $<0.001$ & 14.7 & 19.5 \\
\hline Thinness & $n(\%)$ & $303(8.5)$ & $466(6.2)$ & & & \\
\hline Normal weight & $n(\%)$ & $2,908(81.2)$ & $5,182(68.4)$ & & & \\
\hline Overweight & $n(\%)$ & $326(9.1)$ & $1,419(18.7)$ & & & \\
\hline Obesity & $n(\%)$ & $44(1.2)$ & $511(6.7)$ & & & \\
\hline Maternal BMI $\left(\mathrm{kg} / \mathrm{m}^{2}\right)$ & Median (IQR) & $22.68(20.67,25.42)$ & $22.73(20.88,25.66)$ & 0.010 & 7.8 & 6.2 \\
\hline Maternal weight status & & & & $<0.001$ & 7.8 & 6.2 \\
\hline Thinness $\left(<18.5 \mathrm{~kg} / \mathrm{m}^{2}\right)$ & $n(\%)$ & $230(5.9)$ & $439(5.0)$ & & & \\
\hline Normal weight (18.5 to $24.9 \mathrm{~kg} / \mathrm{m}^{2}$ ) & $n(\%)$ & $2,582(66.7)$ & $5,854(66.3)$ & & & \\
\hline Overweight (25 to $29.9 \mathrm{~kg} / \mathrm{m}^{2}$ ) & $n(\%)$ & $816(21.1)$ & $1,754(19.9)$ & & & \\
\hline Obesity ( $\geq 30 \mathrm{~kg} / \mathrm{m}^{2}$ ) & $n(\%)$ & $244(6.3)$ & $786(8.9)$ & & & \\
\hline Father's occupational class at age 11 years & & & & $<0.001$ & 9.1 & 23.4 \\
\hline I (Professional) & $n(\%)$ & $231(6.1)$ & $401(5.6)$ & & & \\
\hline II (Managerial and technical) & $n(\%)$ & $741(19.4)$ & $3,150(43.7)$ & & & \\
\hline IIIN (Skilled non-manual) & $n(\%)$ & $589(15.4)$ & $913(12.7)$ & & & \\
\hline IIIM (Skilled manual) & $n(\%)$ & $1,306(34.2)$ & $1,578(21.9)$ & & & \\
\hline IV (Partly-skilled) & $n(\%)$ & $722(18.9)$ & $962(13.3)$ & & & \\
\hline V (Unskilled) & $n(\%)$ & $230(6.0)$ & 207 (2.9) & & & \\
\hline
\end{tabular}


Table 2. Adjusted associations of infant weight change with adolescent BMI, estimated using general linear regression models applied to multiple-imputed data ${ }^{a}$

\begin{tabular}{|c|c|c|c|c|c|c|c|c|c|}
\hline & \multicolumn{3}{|c|}{1946 NSHD $(n=4,199)$} & \multicolumn{3}{|c|}{$2001 \operatorname{MCS}(n=9,417)$} & \multicolumn{3}{|c|}{ Between-cohort difference } \\
\hline & $B$ & $95 \% \mathrm{Cl}$ & $P$ & $B$ & $95 \% \mathrm{Cl}$ & $P$ & $B$ & $95 \% \mathrm{Cl}$ & $P$ \\
\hline \multicolumn{10}{|c|}{ BMI Z-score at age 11 years } \\
\hline \multicolumn{10}{|c|}{ Infant weight Z-score change } \\
\hline If $\leq-1$ Z-score & 0.349 & $0.204,0.495$ & $<0.001$ & 0.349 & $0.253,0.495$ & $<0.001$ & 0.000 & $-0.175,0.175$ & $>0.999$ \\
\hline If $>-1$ Z-score & 0.423 & $0.379,0.468$ & $<0.001$ & 0.523 & $0.495,0.551$ & $<0.001$ & 0.099 & $0.046,0.152$ & $<0.001$ \\
\hline \multicolumn{10}{|c|}{ BMI Z-score at age 14 years } \\
\hline \multicolumn{10}{|c|}{ Infant weight Z-score change } \\
\hline If $\leq-1$ Z-score & 0.296 & $0.152,0.440$ & $<0.001$ & 0.294 & $0.188,0.401$ & $<0.001$ & -0.001 & $-0.174,0.172$ & 0.991 \\
\hline If $>-1$ Z-score & 0.359 & $0.315,0.403$ & $<0.001$ & 0.464 & $0.434,0.494$ & $<0.001$ & 0.105 & $0.052,0.159$ & $<0.001$ \\
\hline
\end{tabular}

${ }^{a}$ A separate model for each cohort and each outcome time point was applied to multiple-imputed data. To account for non-linearity, infant weight Z-score change was parameterised using linear splines (i.e., one term for values $\leq-1$ Z-score and one term for values $>-1$ Z-score). Between-cohort differences in exposure estimates were tested using t-tests. Adjustment was made for birth weight Z-score, father's occupational class at age 11 years (transformed to ridit scores), maternal BMI, sex, and exact age of outcome assessment. 
Table 3. Adjusted associations of rapid infant weight gain with adolescent BMI, estimated using general linear regression models applied to multiple-imputed data ${ }^{a}$

\begin{tabular}{|c|c|c|c|c|c|c|c|c|c|}
\hline & \multicolumn{3}{|c|}{1946 NSHD $(n=4,199)$} & \multicolumn{3}{|c|}{$2001 \operatorname{MCS}(n=9,417)$} & \multicolumn{3}{|c|}{ Between-cohort difference } \\
\hline & $B$ & $95 \% \mathrm{Cl}$ & $P$ & $B$ & $95 \% \mathrm{Cl}$ & $P$ & $B$ & $95 \% \mathrm{Cl}$ & $P$ \\
\hline \multicolumn{10}{|l|}{ BMI Z-score at age 11 years } \\
\hline \multicolumn{10}{|l|}{ Infant weight Z-score change } \\
\hline$<-0.67$ (slow) & -0.388 & $-0.475,-0.302$ & $<0.001$ & -0.588 & $-0.649,-0.528$ & $<0.001$ & -0.200 & $-0.305,-0.094$ & $<0.001$ \\
\hline-0.67 to +0.67 (normal) [referent] & -- & -- & -- & -- & -- & -- & -- & -- & -- \\
\hline+0.67 to +1.34 (rapid) & 0.352 & $0.264,0.439$ & $<0.001$ & 0.319 & $0.255,0.383$ & $<0.001$ & 0.033 & $-0.141,0.076$ & 0.555 \\
\hline > +1.34 (very rapid) & 0.573 & $0.466,0.681$ & $<0.001$ & 0.790 & $0.717,0.862$ & $<0.001$ & 0.216 & $0.086,0.346$ & 0.001 \\
\hline \multicolumn{10}{|l|}{ BMI Z-score at age 14 years } \\
\hline \multicolumn{10}{|l|}{ Infant weight Z-score change } \\
\hline$<-0.67$ (slow) & -0.355 & $-0.440,-0.270$ & $<0.001$ & -0.493 & $-0.555,-0.432$ & $<0.001$ & -0.138 & $-0.243,-0.033$ & 0.010 \\
\hline-0.67 to +0.67 (normal) [referent] & -- & -- & -- & -- & -- & -- & -- & -- & -- \\
\hline+0.67 to +1.34 (rapid) & 0.270 & $0.185,0.355$ & $<0.001$ & 0.283 & $0.218,0.347$ & $<0.001$ & 0.013 & $-0.092,0.118$ & 0.814 \\
\hline > +1.34 (very rapid) & 0.508 & $0.407,0.610$ & $<0.001$ & 0.726 & $0.652,0.800$ & $<0.001$ & 0.217 & $0.092,0.342$ & 0.001 \\
\hline
\end{tabular}

a A separate model for each cohort and each outcome time point was applied to multiple-imputed data. Between-cohort differences in exposure estimates were tested using t-tests. Adjustment was made for birth weight Z-score, father's occupational class at age 11 years (transformed to ridit scores), maternal BMI, sex, and exact age of outcome assessment. 
Table 4. Adjusted associations of rapid infant weight gain with adolescent overweight/ obesity (compared to normal weight), estimated using multinomial logistic regression models applied to multiple-imputed data ${ }^{a}$

\begin{tabular}{|c|c|c|c|c|c|c|c|}
\hline & \multicolumn{3}{|c|}{1946 NSHD $(n=4,199)$} & \multicolumn{3}{|c|}{$2001 \operatorname{MCS}(n=9,417)$} & \multirow{2}{*}{$\begin{array}{c}\text { Between-cohort difference }^{\mathbf{b}} \\
P\end{array}$} \\
\hline & $R R R$ & $95 \% \mathrm{Cl}$ & $P$ & $R R R$ & $95 \% \mathrm{Cl}$ & $P$ & \\
\hline \multicolumn{8}{|l|}{ Overweight/ obesity at age 11 years } \\
\hline$<-0.67$ (slow) & 0.556 & $0.388,0.796$ & 0.001 & 0.427 & $0.364,0.501$ & $<0.001$ & 0.189 \\
\hline-0.67 to +0.67 (normal) [referent] & -- & -- & -- & -- & -- & -- & \\
\hline$>+1.34$ (very rapid) & 2.940 & $1.983,4.358$ & $<0.001$ & 3.143 & $2.667,3.703$ & $<0.001$ & 0.758 \\
\hline \multicolumn{8}{|l|}{ Overweight/ obesity at age 14 years } \\
\hline \multicolumn{8}{|l|}{ Infant weight Z-score change } \\
\hline$<-0.67$ (slow) & 0.576 & $0.409,0.811$ & 0.002 & 0.493 & $0.421,0.578$ & $<0.001$ & 0.425 \\
\hline-0.67 to +0.67 (normal) [referent] & -- & -- & -- & -- & -- & -- & \\
\hline+0.67 to +1.34 (rapid) & 1.845 & $1.359,2.504$ & $<0.001$ & 1.508 & $1.297,1.753$ & $<0.001$ & 0.241 \\
\hline
\end{tabular}

$R R R$, relative risk ratio

a A separate model for each cohort and each outcome time point was applied to multiple-imputed data. Between-cohort differences in exposure estimates were tested using t-tests. Adjustment was made for birth weight Z-score, father's occupational class at age 11 years (transformed to ridit scores), maternal BMI, sex, and exact age of outcome assessment.

b Between-cohort differences for the RRR are not shown as they are not intuitive as they are not equal to the estimate for the 2001 MCS minus the estimate for the 1946 NSHD. 
Table 5. Blinder-Oaxaca decomposition of differences in adolescent BMI

between the 1946 NSHD and 2001 MCS due to infant weight gain ${ }^{a}$

B $\quad 95 \% \mathrm{Cl} \quad P$

BMI Z-score at age 11 years

Mean predictions

\begin{tabular}{lccc}
2001 MCS $(n=9,417)$ & 0.564 & $0.540,0.588$ & $<0.001$ \\
1946 NSHD $(n=4,199)$ & 0.003 & $-0.028,0.034$ & 0.841 \\
Difference & 0.561 & $0.521,0.600$ & $<0.001$ \\
Characteristics (Infant weight Z-score change) & 0.051 & $0.033,0.070$ & $<0.001$ \\
Coefficients (Infant weight Z-score change) & 0.127 & $-0.065,0.320$ & 0.195 \\
Interaction (Infant weight Z-score change) & 0.012 & $0.005,0.019$ & 0.001 \\
\hline
\end{tabular}

BMI Z-score at age 14 years

Mean predictions

$\begin{array}{lccc}2001 \text { MCS }(n=9,417) & 0.468 & 0.443,0.493 & <0.001 \\ 1946 \text { NSHD }(n=4,199) & 0.005 & -0.026,0.036 & 0.754 \\ \text { Difference } & 0.463 & 0.424,0.502 & <0.001 \\ \text { Characteristics (Infant weight Z-score change) } & 0.044 & 0.028,0.060 & <0.001 \\ \text { Coefficients (Infant weight Z-score change) } & 0.136 & -0.063,0.334 & 0.179 \\ \text { Interaction (Infant weight Z-score change) } & 0.013 & 0.005,0.020 & 0.001\end{array}$

a Blinder-Oaxaca three-way decomposition was applied to the multiple-imputed data using the same regression models as those presented in Table 2. The presented characteristics, coefficients, and interaction estimates for infant weight Z-score change are, therefore, adjusted for covariates. Characteristics reflect the increase in BMI Z-score in the 1946 NSHD if that cohort had the same infant weight Z-score change values as the $2001 \mathrm{MCS}$. Coefficients reflect the increase in BMI Zscore in the 1946 NSHD when applying the 2001 MCS coefficients to the 1946 NSHD infant weight Zscore change values. The interaction term measures the simultaneous effect of differences in characteristics and coefficients, and is essentially error. 